\title{
Long-Term Percutaneous Coronary Intervention Outcomes of Patients with Chronic Kidney Disease in the Era of Second-Generation Drug-Eluting Stents
}

\author{
Wojciech Wańha ${ }^{a} \quad$ Damian Kawecki $^{b}$ Tomasz Roleder ${ }^{a}$ \\ Aleksandra Pluta $^{a}$ Kamil Marcinkiewicz ${ }^{a}$ Beata Morawiec ${ }^{b}$ \\ Janusz Dolab Sylwia Gładysz ${ }^{a}$ Tomasz Pawłowski ${ }^{a} \quad$ Grzegorz Smolka ${ }^{a}$ \\ Andrzej Ochała ${ }^{a}$ Ewa Nowalany-Kozielskab Wojciech Wojakowski ${ }^{a}$ \\ a Third Division of Cardiology, Medical University of Silesia, Katowice, and ${ }^{b}$ Second Division \\ of Cardiology, Medical University of Silesia, Zabrze, Poland
}

\section{Key Words}

Percutaneous coronary intervention · Drug-eluting stents · Chronic kidney disease ·

Bleeding complications

\begin{abstract}
Background: The following registry (Katowice-Zabrze retrospective registry) aimed to assess the influence of a chronic kidney disease (CKD) on long-term clinical outcomes in patients undergoing percutaneous coronary intervention (PCI) using either first-generation (DES-I) or second-generation (DES-II) drug-eluting stents. Methods: The study group consisted of 1,908 consecutive patients, of whom 331 (17.3\%) had CKD. CKD was defined as an estimated glomerular filtration rate of $<60 \mathrm{~mL} / \mathrm{min} / \mathrm{m}^{2}$. We evaluated the major adverse cardiac and cerebral events (MACCE), i.e., the composite of death, myocardial infarction (MI), stroke, and target vessel revascularization at the 12-month follow-up. Results: CKD patients had a lower left ventricular ejection fraction and more often a history of MI and PCI. Coronary angiography revealed that multivessel coronary artery disease, intracoronary thrombus, and extensive calcifications were more frequent in patients with CKD. However, the SYNTAX score did not vary between patients with or without CKD. There was a higher rate of in-hospital bleedings requiring blood transfusion in patients with CKD. At the 1-year follow-up, MACCE (17.8 vs. $12.6 \%$, $\mathrm{HR}=1.46[95 \% \mathrm{CI} 1.05-2.03], p=0.009)$ and death (8.4 vs. 2.3\%, HR = 3.9 [95\% CI 2.0-7.5], $p<0.001$ ) were more often observed in CKD patients. Multivariable Cox analysis revealed that CKD was an independent risk predictor of death after PCI at the 1-year follow-up (HR $=2.1$
\end{abstract}

Wojciech Wańha, MD, PhD

Third Division of Cardiology, Medical University of Silesia

Ziołowa Str. 45

PL-40-635 Katowice (Poland)

E-Mail wojciech.wanha@gmail.com 
Wańha et al.: Long-Term Percutaneous Coronary Intervention Outcomes of Patients with Chronic Kidney Disease in the Era of Second-Generation Drug-Eluting Stents

[95\% CI 1.2-3.6], $p=0.004)$. In comparison to DES-I, the use of DES-II did not decrease the adverse effect of CKD on MACCE. Conclusion: CKD patients had an increased risk of in-hospital bleeding requiring blood transfusion and a higher risk of MACCE and death at the 12-month follow-up. The use of second-generation DES did not improve clinical outcomes in patients with CKD at the 12-month follow-up.

(c) 2016 S. Karger AG, Base

\section{Background}

Chronic kidney disease (CKD) is relatively frequent in patients presenting with acute coronary syndrome (ACS) (30-40\%) [1], and increases the risk of death, myocardial infarction (MI), stent thrombosis (ST) and bleeding complications of percutaneous coronary interventions (PCI) $[2,3]$. Previous observation documented that the relation between the risk of adverse cardiovascular (CV) events and renal function was inverse. The HOPE study showed that a creatinine level $>1.4 \mathrm{mg} / \mathrm{dL}$ or a glomerular filtration rate (GFR) $<65 \mathrm{~mL} / \mathrm{min} / \mathrm{m}^{2}$ was associated with worse clinical outcomes [4]. Hence, such patients require an adequate risk assessment and a multidisciplinary approach to avoid complications during and after PCI. Similar to patients without CKD, an early revascularization compared to medical therapy was associated with better survival in all CKD stages including dialysis patients [5, 6]. Further analysis also proved that drug-eluting stents (DES) had better outcomes, as compared to bare metal stents, in terms of MI and death and target vessel revascularization (TVR) [7, 8]. Introduction of second-generation DES (DES-II) brought benefit to patients without CKD, but there is still a debate whether DES-II improve clinical outcomes in CKD patients.

Because CKD patients usually do not meet inclusion criteria for large clinical trials, the current registry, consisting of a representative group of the general population, may broadly address the problem. Hence, the present report analyzed the impact of CKD on clinical outcomes in patients treated either with DES-I or DES-II.

\section{Methods and Study Population}

The Katowice-Zabrze retrospective registry included 1,916 consecutive patients treated with either first-generation (paclitaxel, sirolimus; 33.6\%) or second-generation (everolimus, zotarolimus, biolimus A9, $66.4 \%$ ) DES. Estimated GFR (eGFR) was assessed on admission and before PCI. CKD was defined as eGFR $<60$ $\mathrm{mL} / \mathrm{min} / 1.73 \mathrm{~m}^{2}$ calculated using the Modification of Diet in Renal Disease method [9]. An eGFR $<60 \mathrm{~mL} /$ $\mathrm{min} / 1.73 \mathrm{~m}^{2}$ is referred to as stage $2 \mathrm{CKD}$. For our analysis, 8 patients were excluded because eGFR has not been measured. Baseline characteristics, cardiac history, risk factors, medications, and angiographic and procedural data were obtained and recorded. Angiographic data were collected in all patients undergoing PCI and recorded in the CV information registry. The SYNTAX score was calculated in all patients except those after coronary artery bypass graft. The primary study endpoint was DES efficacy and safety in all patients. DES efficacy was measured as the presence of major adverse cardiac and cerebral events (MACCE). MACCE was defined as MI, TVR, death, or stroke at the 1-year follow-up. The safety of DES was defined as definite stent thrombosis (acute, subacute, late). TVR, definite stent thrombosis, acute, subacute, and late stent thrombosis were defined according to the definitions of endpoints for clinical trials [10]. Data regarding longterm clinical outcomes (mortality and MACCE) were obtained from the database of the National Health Fund Service (Ministry of Health).

\section{Statistics}

Statistical analysis was performed using MedCalc Software (v.12, Ostend, Belgium). Quantitative variables are presented as mean \pm standard deviation and median with interquartile range (Q1-Q3). Qualitative data are expressed as crude values and/or percentages. Between-group differences were assessed using the 
Wańha et al.: Long-Term Percutaneous Coronary Intervention Outcomes of Patients with Chronic Kidney Disease in the Era of Second-Generation Drug-Eluting Stents

Table 1. Patient characteristics, risk factors, and clinical presentation according to the presence of CKD

\begin{tabular}{|c|c|c|c|}
\hline & $\begin{array}{l}\text { CKD+ } \\
n=331(17.3 \%)\end{array}$ & $\begin{array}{l}\text { CKD- } \\
n=1,577(82.7 \%)\end{array}$ & $p$ \\
\hline \multicolumn{4}{|l|}{ Demographic data } \\
\hline Age, years & 71 [64-76] & $61[56-69]$ & $<0.001$ \\
\hline Male & $163(49.2)$ & $1,066(67.5)$ & $<0.001$ \\
\hline Female & $168(50.7)$ & $511(32.4)$ & $<0.001$ \\
\hline BMI & 29 [26-32] & $28.4[25-31]$ & 0.043 \\
\hline \multicolumn{4}{|l|}{ Discharge diagnosis } \\
\hline UA & $246(74.3)$ & $1,247(79.0)$ & 0.066 \\
\hline NSTEMI & $68(20.5)$ & $216(13.6)$ & 0.002 \\
\hline STEMI/LBBB & $17(5.1)$ & $114(7.2)$ & 0.211 \\
\hline \multicolumn{4}{|l|}{ CAD history } \\
\hline Previous MI & $179(54.0)$ & $734(46.5)$ & 0.014 \\
\hline Previous PCI & $203(61.3)$ & $858(54.4)$ & 0.024 \\
\hline Previous CABG & $80(24.1)$ & $317(20.1)$ & 0.113 \\
\hline \multicolumn{4}{|l|}{ CAD risk factors } \\
\hline Hypertension & $305(92.1)$ & $1,331(84.4)$ & $<0.001$ \\
\hline Dyslipidemia & $212(64.0)$ & $1,046(66.3)$ & 0.464 \\
\hline Diabetes mellitus & $167(50.4)$ & $548(34.7)$ & $<0.001$ \\
\hline Smoking & 43 (12.9) & $418(26.5)$ & $<0.001$ \\
\hline \multicolumn{4}{|l|}{ Concomitant disease } \\
\hline Anemia & $69(20.8)$ & $147(9.3)$ & $<0.001$ \\
\hline Cancer & $31(9.3)$ & $84(5.3)$ & 0.007 \\
\hline COPD & $33(9.9)$ & $84(5.3)$ & 0.002 \\
\hline PAD & $58(17.5)$ & $160(10.1)$ & $<0.001$ \\
\hline Length of hospital stay, days & $5[4-8]$ & $4[3-6]$ & $<0.001$ \\
\hline Left ventricular function & $50[40-55]$ & $55[46-60]$ & $<0.001$ \\
\hline \multicolumn{4}{|l|}{ Laboratory } \\
\hline $\mathrm{GFR}, \mathrm{mL} / \mathrm{min} / 1.73 \mathrm{~m}^{2}$ & $49[40-55]$ & $87[75-96]$ & $<0.001$ \\
\hline Creatinine, $\mathrm{mg} / \mathrm{dL}$ & $1.2[1.1-1.5]$ & $0.8[0.7-0.9]$ & $<0.001$ \\
\hline Hemoglobin on admission, g/dL & $13[12-14]$ & $14[13-15]$ & $<0.001$ \\
\hline \multicolumn{4}{|l|}{ Clinical status on admission } \\
\hline $\mathrm{HR}, \mathrm{bpm}$ & $71[60-80]$ & $70[60-77]$ & 0.076 \\
\hline $\mathrm{SBP}, \mathrm{mm} \mathrm{Hg}$ & $130[120-145]$ & $130[120-150]$ & 0.780 \\
\hline \multicolumn{4}{|l|}{$\mathrm{CCS}$} \\
\hline II & $87(26.2)$ & $508(32.2)$ & 0.040 \\
\hline III-IV & $244(73.7)$ & $1,069(67.7)$ & \\
\hline \multicolumn{4}{|l|}{ KILLIP } \\
\hline I-II & $83(97.6)$ & $321(97.2)$ & 0.851 \\
\hline III-IV & $2(2.3)$ & $9(2.7)$ & \\
\hline GRACE score $>140$ points & $37(77.0)$ & $99(51.5)$ & 0.002 \\
\hline
\end{tabular}

Values are median [ranges] or $n(\%)$. BMI, body mass index; UA, unstable angina; NSTEMI, non-STsegment elevation myocardial infarction; STEMI, ST-segment elevation myocardial infarction; LBBB, left bundle branch block; CAD, coronary artery disease; MI, myocardial infarction; PCI, percutaneous coronary intervention; $\mathrm{CABG}$, coronary artery bypass graft; $\mathrm{CKD}$, chronic kidney disease; COPD, chronic obstructive pulmonary disease; PAD, peripheral artery disease; HR, heart rate; SBP, systolic blood pressure. CKD was defined as estimated GFR $<60 \mathrm{~mL} / \mathrm{min} / 1.73 \mathrm{~m}^{2}$ calculated using the Modification of Diet in Renal Disease method.

Mann-Whitney U test for quantitative variables and the $\chi^{2}$ test for qualitative variables. Data distribution was verified with the Smirnov-Kolmogorov test. Kaplan-Meier curves were used to present the unadjusted timeto-event data for investigated endpoints. Additionally, multivariable modeling was performed using the Cox proportional hazards method to assess the adjusted association between all endpoints and DES type. All tests were 2 -tailed. $p<0.05$ was considered significant. 
Table 2. Drug therapy according to the presence of CKD

\begin{tabular}{lccr}
\hline & CKD + & CKD & $p$ \\
& $n=331(17.3 \%)$ & $n=1,577(82.7 \%)$ & \\
\hline ASA & $324(98.4)$ & $1,555(98.7)$ & 0.848 \\
Clopidogrel & $325(98.7)$ & $1,556(98.8)$ & 0.863 \\
Glycoprotein IIb/IIIa inhibitors & $11(3.3)$ & $84(5.3)$ & 0.166 \\
$\beta$-Blockers & $297(90.2)$ & $1,413(89.7)$ & 0.861 \\
ACEI & $238(72.3)$ & $1,271(80.7)$ & $<0.001$ \\
ARB & $39(11.8)$ & $190(12.0)$ & 0.986 \\
Statins & $303(92.0)$ & $1,480(94.0)$ & 0.235 \\
Ca blockers & $122(37.0)$ & $399(25.3)$ & $<0.001$ \\
VKA & $34(10.2)$ & $59(3.7)$ & $<0.001$ \\
Prasugrel & - & 0.3 & 0.666 \\
\hline
\end{tabular}

Figures are numbers, with percentages in parentheses. ASA, acetylsalicylic acid; VKA, vitamin K antagonists; ACEI, angiotensin-converting enzyme inhibitor; ARB, angiotensin receptor blocker; Ca blockers, calcium channel blockers.

\section{Results}

\section{Demographics}

During the 24 months between January 2009 and December 2010, 1,908 patients were admitted with the following diagnoses: unstable angina $(n=1,493,78.2 \%)$, non-ST-segment elevation myocardial infarction $(n=284,14.8 \%)$, and ST-segment elevation myocardial infarction (STEMI/left bundle branch block) ( $n=131,6.8 \%)$. There were 679 females $(35.5 \%)$ and 1,229 males (64.5\%). CKD was present in 331 (17.3\%) patients (163 men [49.2\%] and 168 women [50.7\%], $p<0.001)$. According to the eGFR, the most common type of CKD was moderate CKD, i.e., between stages 3A and 3B (eGFR 30-59 mL/min $/ 1.73 \mathrm{~m}^{2} ; n=299$ [90.3\%]), followed by severe CKD, i.e., stage 4 (eGFR $\left.15-29 \mathrm{~mL} / \mathrm{min} / 1.73 \mathrm{~m}^{2} ; n=21[6.3 \%]\right)$, and the least common type was end-stage CKD, i.e., stage 5 (eGFR $<15 \mathrm{~mL} / \mathrm{min} / 1.73 \mathrm{~m}^{2} ; n=11$ [3.3\%]). In the total population of ACS patients, the median eGFR value was 82 (IQR: 66.8-94.2 mL/ $\min / 1.73 \mathrm{~m}^{2}$ ) and the respective values for STEMI/left bundle branch block, non-ST-segment elevation myocardial infarction, and unstable angina were 87.7 (IQR: 74.1-101.0 mL/min $/ 1.73$ $\mathrm{m}^{2}$ ), 76.8 (IQR: $60.9-91.7 \mathrm{~mL} / \mathrm{min} / 1.73 \mathrm{~m}^{2}$ ), and 82.9 (IQR: $67.5-93.9 \mathrm{~mL} / \mathrm{min} / 1.73 \mathrm{~m}^{2}$ ).

\section{Comorbidities and Chronic Medications}

Patients with CKD presented a higher angina Canadian Cardiovascular Society class at baseline, were older, more often females, and had a higher prevalence of comorbidities (hypertension, diabetes, lung disease, peripheral artery disease, and anemia). Also, they more often had Global Registry of Acute Coronary Events (GRACE) risk scores over 140 points (72.0 vs. $51.5 \%, p=0.002$ ). They more frequently had a history of MI and PCI in comparison to patients without CKD. The patient's data are summarized in Table 1 . There were no differences in peri- and postprocedural medical treatment regimens in both groups except that CKD patients less often received angiotensin-converting enzyme inhibitors, but more often vitamin $\mathrm{K}$ antagonists and calcium channel blockers (Table 2).

\section{Left Ventricular Function}

Left ventricular ejection fraction (LVEF) values were available in $98.7 \%$ of all patients. In the general population, the LVEF was normal in $70 \%$ patients, moderately reduced $(31-50 \%)$ in 
Wańha et al.: Long-Term Percutaneous Coronary Intervention Outcomes of Patients with Chronic Kidney Disease in the Era of Second-Generation Drug-Eluting Stents

Table 3. Angiographic and procedural data according to the presence of CKD

\begin{tabular}{|c|c|c|c|}
\hline & $\begin{array}{l}\text { CKD+ } \\
n=331(17.3 \%)\end{array}$ & $\begin{array}{l}\text { CKD- } \\
n=1,577(82.7 \%)\end{array}$ & $p$ \\
\hline SYNTAX score, points & $16[8-26]$ & $14[8-23]$ & 0.314 \\
\hline DES-I & $100(30.2)$ & $542(34.3)$ & 0.164 \\
\hline DES-II & 231 (69.7) & $1,035(65.6)$ & \\
\hline \multicolumn{4}{|c|}{ Number of vessels with significant stenosis } \\
\hline 1 & $99(29.9)$ & $611(38.7)$ & 0.003 \\
\hline 2 & $119(35.9)$ & $559(35.4)$ & 0.911 \\
\hline 3 & $113(34.1)$ & $407(25.8)$ & 0.002 \\
\hline \multicolumn{4}{|l|}{ Type of the culprit lesion (AHA/ACC) } \\
\hline A & 76 (22.9) & $347(22.0)$ & 0.757 \\
\hline B & $204(61.6)$ & $991(63.2)$ & 0.725 \\
\hline $\mathrm{B} / \mathrm{C}$ & $5(1.5)$ & $7(0.4)$ & 0.064 \\
\hline $\mathrm{C}$ & $46(13.8)$ & $232(14.7)$ & 0.767 \\
\hline \multicolumn{4}{|l|}{ Target vessel } \\
\hline Left main & $27(8.1)$ & $98(6.2)$ & 0.239 \\
\hline Left anterior desc & $142(42.9)$ & $829(52.5)$ & 0.001 \\
\hline Left circumflex & 59 (17.8) & $278(18.1)$ & 0.995 \\
\hline Right coronary artery & $75(22.6)$ & $304(19.2)$ & 0.184 \\
\hline Arterial bypass graft & $2(0.6)$ & $9(0.5)$ & 0.744 \\
\hline Saphenous vein graft & $26(7.8)$ & $59(3.7)$ & 0.001 \\
\hline Extensive calcifications & $23(6.9)$ & $63(3.9)$ & $<0.001$ \\
\hline Stent thrombosis in culprit lesion & $10(3.0)$ & $24(1.6)$ & $<0.001$ \\
\hline Average stent diameter, mm & $3[2.5-3.5]$ & $3[2.7-3.5]$ & 0.334 \\
\hline Total stent length, mm & $23[16-30]$ & $22[15-28]$ & 0.248 \\
\hline
\end{tabular}

Values are $n(\%)$ or median [ranges]. DES-I, first-generation drug-eluting stents; DES-II, second-generation drug-eluting stents.

$24 \%$ and severely $(\leq 30 \%)$ reduced in $6 \%$ of patients. Patients with CKD had lower LVEF values as compared to patients with no CKD (50, IQR 40-55 vs. 55, IQR 46-60, $p<0.001$ ) (Table 1).

\section{Interventional Treatment and Reperfusion Strategy}

Although the SYNTAX score was comparable in patients with or without CKD, patients with CKD more often had multivessel disease, evidence of thrombus in culprit lesion, and extensive coronary calcifications. First- and second-generation DES were used with similar frequency in patients with and without CKD (Table 3).

\section{In-Hospital and 30-Day Outcomes}

There was a significantly higher rate of in-hospital bleedings requiring blood transfusion in patients with CKD ( 3.3 vs. $0.3 \%, p<0.001$ ) as compared to those with normal renal function (Fig. 1), especially in patients with CKD and reduced LVEF (CKD 1.7\% vs. non-CKD 0.5\%, $p<$ $0.001)$. Patients with CKD more often had cardiogenic shock $(2.4$ vs. $0.6 \%, p=0.006)$ and resuscitated cardiac arrest ( 3.0 vs. $0.8 \%, p=0.002$ ) during hospitalization. Also, the risk of respiratory insufficiency was higher in CKD ( 2.1 vs. $0.2, p<0.001)$. Even so, we did not observe differences in rates of acute and subacute ST in patients with and without CKD (Table 4).

\section{Twelve-Month Outcomes}

The 12-month follow-up showed that there was a 46\% higher risk of MACCE (17.8 vs. $12.6 \%, \mathrm{HR}=1.46[95 \% \mathrm{CI} 1.05-2.03], p=0.009$ ) and death (8.4 vs. $2.3 \%, \mathrm{HR}=3.9[95 \% \mathrm{CI}$ 
CardioRenal

Medicine

Fig. 1. In-hospital follow-up: bleeding complications according to the presence of CKD.

\begin{tabular}{l|l}
\hline Cardiorenal Med 2017;7:85-95 \\
\hline DOI: 10.1159/000452745 & $\begin{array}{l}\text { @ 2016 S. Karger AG, Basel } \\
\text { www.karger.com/crm }\end{array}$ \\
\hline
\end{tabular}

Wańha et al.: Long-Term Percutaneous Coronary Intervention Outcomes of Patients with Chronic Kidney Disease in the Era of Second-Generation Drug-Eluting Stents

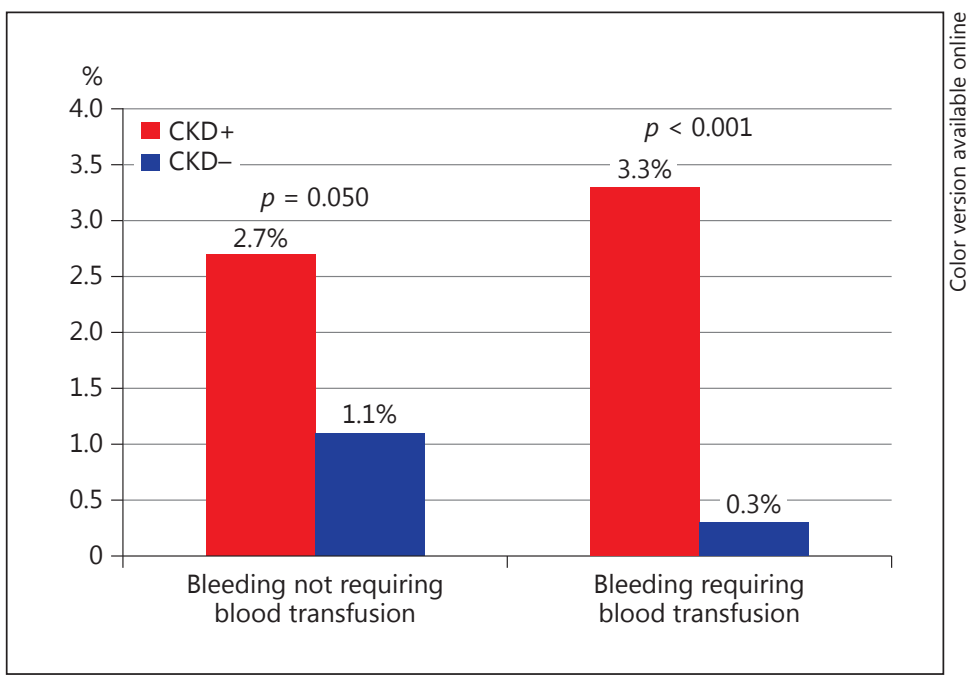

Table 4. In-hospital, 30-day and 1-year follow-up according to the presence of CKD

\begin{tabular}{lcrr}
\hline & $\begin{array}{l}\text { CKD }+ \\
n=331(17.3 \%)\end{array}$ & $\begin{array}{l}\text { CKD- } \\
n=1,577(82.7 \%)\end{array}$ & $p$ \\
\hline $\begin{array}{l}\text { In-hospital adverse events } \\
\quad \text { Cardiogenic shock }\end{array}$ & & $10(0.6)$ & 0.006 \\
$\quad$ Respiratory insufficiency & $7(2.4)$ & $4(0.2)$ & $<0.001$ \\
$\quad$ Cardiac arrest & $10(3.0)$ & $13(0.8)$ & $<0.001$ \\
Stent thrombosis & $0(0)$ & $10(0.6)$ & 0.301 \\
$\quad$ Acute stent thrombosis & $1(0.3)$ & $6(0.3)$ & 0.775 \\
$\quad$ Subacute stent thrombosis & $3(0.9)$ & $2(0.1)$ & 0.454 \\
$\quad$ Late stent thrombosis & & & \\
\hline
\end{tabular}

Figures are numbers, with percentages in parentheses.

2.0-7.5], $p<0.001$ ) in CKD patients. We did not observe differences in rates of TVR, MI and stroke (Fig. 2, 3). The rate of late ST did not differ significantly between patients with and without CKD ( $p=0.454)$ (Table 4). Multivariable Cox analysis revealed that CKD was an independent risk factor for death (HR $=2.1$ [95\% CI 1.2-3.6], $p=0.004$ ) after PCI at the 1-year follow-up (Table 5). There was no difference in death and MACCE according to the type of DES (DES-I vs. DES-II) (Fig. 4, 5).

\section{Discussion}

The following report revealed that a high proportion (17.3\%) of patients hospitalized with ACS and DES implantation suffered from CKD, and confirmed previous data that CKD is a strong risk factor of death at the 12-month follow-up [11,12]. Furthermore, our study is the first to present that the introduction of DES-II did not bring benefit in CKD patients at the 12-month follow-up, which is a contrast to the non-CKD population [13].

Similarly to other studies, CKD patients in the presented registry carried a higher risk of adverse events, they were older $[2,11,12,14-16]$, were more often females $[11,14,16]$, and 
CardioRenal
Medicine

Fig. 2. Kaplan-Meier curves for all-cause mortality in patients with and without CKD.

Fig. 3. Kaplan-Meier curves for MACCE in patients with and without CKD.

Fig. 4. Kaplan-Meier curves for all-cause mortality in patients with CKD treated with DES-I vs. DES-II.

\begin{tabular}{l|l}
\hline \multicolumn{2}{l}{ Cardiorenal Med 2017;7:85-95 } \\
\hline DOI: 10.1159/000452745 & $\begin{array}{l}\text { @ 2016 S. Karger AG, Basel } \\
\text { www.karger.com/crm }\end{array}$ \\
\hline
\end{tabular}

Wańha et al.: Long-Term Percutaneous Coronary Intervention Outcomes of Patients with Chronic Kidney Disease in the Era of Second-Generation Drug-Eluting Stents
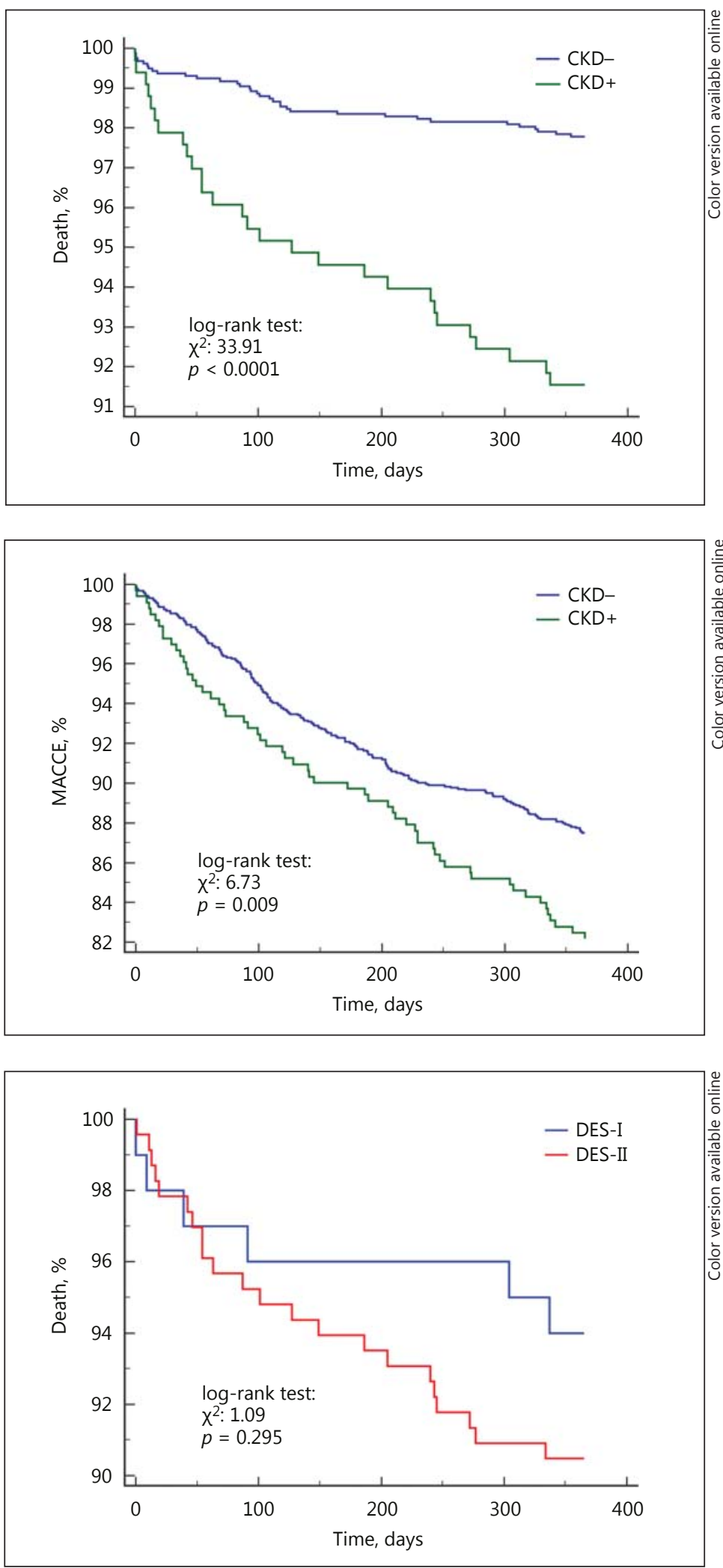
Wańha et al.: Long-Term Percutaneous Coronary Intervention Outcomes of Patients with Chronic Kidney Disease in the Era of Second-Generation Drug-Eluting Stents

Fig. 5. Kaplan-Meier curves for MACCE in patients with CKD treated with DES-I vs. DES-II.

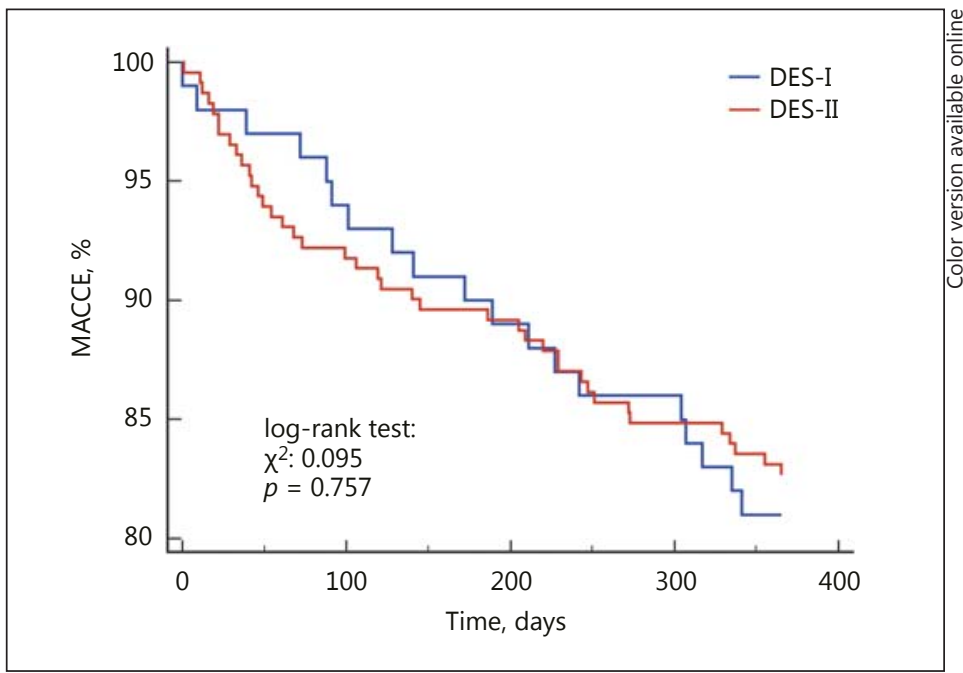

Table 5. Multivariable Cox analysis

\begin{tabular}{lrll}
\hline & $p$ & HR & $95 \%$ CI \\
\hline Chronic kidney disease & 0.004 & 2.175 & $1.28-3.69$ \\
Anemia & 0.334 & 1.342 & $0.73-2.49$ \\
Diabetes mellitus & 0.088 & 1.554 & $0.93-2.57$ \\
PAD & 0.007 & 2.213 & $1.24-3.93$ \\
LVEF $<50 \%$ & $<0.001$ & 6.138 & $2.99-12.58$ \\
Age $>65$ years & 0.004 & 2.3851 & $1.32-4.28$ \\
Previous MI & 0.723 & 1.100 & $0.65-1.86$ \\
\hline
\end{tabular}

PAD, peripheral artery disease; LVEF, left ventricular function; MI, myocardial infarction.

had a higher percentage of comorbidities, such as hypertension [11, 14-16], diabetes [12, 15, $16]$, peripheral artery disease $[11,16]$, and more severe CV disease $[14,15]$.

In addition to that, these patients more often had a history of CV events, myocardial revascularization (PCI, coronary artery bypass graft) and had a higher GRACE risk score as compared to patients without CKD, which was also observed in other studies $[15,16]$. Besides that, the current analysis revealed that only $48.9 \%$ patients with MI had normal LVEF, and moderate and severe LVEF dysfunction was significantly more frequent in patients with CKD.

It is well proven that patients with CKD have a worse prognosis compared with patients with normal renal function $[11,12]$. As observed in other studies, the incidence of adverse CV events during hospitalization was higher in CKD patients $[12,17]$. In the present study, patients with CKD more often had cardiogenic shock and cardiac arrest during hospitalization. In the 12-month follow-up, rates of MACCE were also significantly higher in patients with CKD.

Moreover, survival for patients with CKD was lower than for those without CKD. Several studies demonstrated the adverse effects of CKD. Barthelemy et al. [14] provided evidence that patients with CKD had an increased risk of CV death and MACCE at the 1-year follow-up, with a stepwise increase according to creatinine clearance. Manjunath et al. [18] reported 


\section{CardioRenal Medicine}

\begin{tabular}{l|l}
\hline \multicolumn{2}{l}{ Cardiorenal Med 2017;7:85-95 } \\
\hline DOI: 10.1159/000452745 & $\begin{array}{l}\text { @ 2016 S. Karger AG, Basel } \\
\text { www.karger.com/crm }\end{array}$ \\
\hline
\end{tabular}

Wańha et al.: Long-Term Percutaneous Coronary Intervention Outcomes of Patients with Chronic Kidney Disease in the Era of Second-Generation Drug-Eluting Stents

that the level of kidney function is an independent risk factor for CVD, de novo CVD, and allcause mortality in elderly subjects. However, the creatinine clearance threshold value that predicts possible adverse CV events would be most helpful in deciding on optimal intervention to improve outcomes.

Santopinto et al. [2] reported that the value of creatinine clearance is an important independent predictor of major bleeding in ACS patients. In the current study, there was an increase in bleedings requiring blood transfusion in patients with CKD. The association of CKD with the incidence of major bleeding was also related to a higher risk in a subpopulation of patients with a reduction in LVEF. In patients with reduced LVEF, the risk of bleeding requiring blood transfusion was higher when CKD was present. Data from the other studies showed a strong association between CKD and increased risk of bleeding in patients with ACS managed invasively $[19,20]$. Bleeding rates are more than 3 -fold higher in patients with nonST-segment elevation ACS with CKD compared with patients without CKD [17]. According to the VALIANT Trial baseline, renal insufficiency is one of the independent predictors of gastrointestinal bleeding in patients with STEMI. Moreover, a $10 \mathrm{~mL} / \mathrm{min} / 1.73 \mathrm{~m}^{2}$ decrement in eGFR was associated with $18 \%$ increase in the hazard of gastrointestinal bleeding [20]. In the study by Mathis and Gugger [19], the major influences on bleeding risk appeared to be creatinine clearance $<30 \mathrm{~mL} / \mathrm{min} / \mathrm{m}^{2}$, whereas other markers of renal function, including serum creatinine value and serum creatinine at a cutoff level of $1.5 \mathrm{mg} / \mathrm{dL}$ did not predict bleeding events. All of that together suggests a need for an individualized approach with adequate antiplatelet treatment in patients with CKD to decrease thrombotic events without increasing bleeding [21, 22].

Analysis of available angiographic data demonstrated that the population of patients with and without CKD differed in terms of the complexity of coronary atherosclerotic lesions. Patients with CKD more often had a multivessel disease and PCI of saphenous vein graft as compared to patients with a normal eGFR, which is in keeping with previous observations $[11,14,16,23]$. In addition to that, CKD patients more often had ST at culprit lesion in our group, which confirmed results of Miao et al. [24]. Data from other studies showed that PCI with DES-II in a real-world population is associated with lower risk of clinically meaningful restenosis, ST, and a lower risk of death compared with DES-I [25, 26]. There is limited data comparing DES-I with DES-II in CKD. Our results suggest that the use of new-generation DES (everolimus-, zotarolimus-, and biolimus-eluting stents) in CKD patients does not attenuate the high risk of MACCE and death at the 1-year follow-up. This finding echoes Chan et al. [27] who compared DES-I and DES-II in CKD, but in a 2-year follow-up. As in our study, they did not observe any significant difference in terms of safety and efficacy between the 2 generations of DES. It seemed that a general worse survival of patients with CKD shadowed the benefits of DES-II implantation. Moreover, we had previously shown that the use of DES-II versus DES-I in patients with anemia is associated with the same risk of MACCE and TVR at the 1-year follow-up [28], but in diabetic patients DES-II has a lower risk of ST and similar MACCE rate compared to DES-I [29].

\section{Study Limitations}

There are several limitations of the study. First of all, it was not a randomized, but a retrospective study. On the other hand, in our opinion, the limitation is offset (at least in part) by the "all-comer" inclusion criteria, $100 \%$ follow-up rate and conformation of the endpoints by the National Health Service database. Secondly, data about the pharmacotherapy before the admission and data about the adherence to dual antiplatelet therapy after PCI were unavailable. 
Wańha et al.: Long-Term Percutaneous Coronary Intervention Outcomes of Patients with Chronic Kidney Disease in the Era of Second-Generation Drug-Eluting Stents

\section{Conclusion}

CKD patients had an increased risk of in-hospital bleeding requiring blood transfusion and had a higher risk of death at the 12-month follow-up. Unfortunately, the use of secondgeneration DES did not decrease the risk of MACCE in CKD patients.

\section{Statement of Ethics}

The Institutional Ethics Committee has been approached and their decision was that the registry does not require formal approval. The patients' data were anonymized and as such processed and statistically analyzed. The patients' data were protected according to the requirements of Polish law and hospital SOPs.

\section{Disclosure Statement}

The authors do not have any financial disclosures (i.e. grants, funding, support, etc.), financial relationships or conflicts of interest regarding the content herein.

\section{References}

1 Szummer K, et al: Relation between renal function, presentation, use of therapies and in-hospital complications in acute coronary syndrome: data from the SWEDEHEART register. J Intern Med 2010;268:40-49.

2 Santopinto JJ, et al: Creatinine clearance and adverse hospital outcomes in patients with acute coronary syndromes: findings from the global registry of acute coronary events (GRACE). Heart 2003;89:1003-1008.

3 de la Torre-Hernandez JM, et al: Drug-eluting stent thrombosis: results from the multicenter Spanish registry ESTROFA (Estudio ESpanol sobre TROmbosis de stents FArmacoactivos). J Am Coll Cardiol 2008;51:986-990.

4 Mann JF, et al: Renal insufficiency as a predictor of cardiovascular outcomes and the impact of ramipril: the HOPE randomized trial. Ann Intern Med 2001;134:629-636.

5 Szummer K, et al: Influence of renal function on the effects of early revascularization in non-ST-elevation myocardial infarction: data from the Swedish Web-System for Enhancement and Development of EvidenceBased Care in Heart Disease Evaluated According to Recommended Therapies (SWEDEHEART). Circulation 2009;120:851-858.

6 Huang HD, et al: Patients with severe chronic kidney disease benefit from early revascularization after acute coronary syndrome. Int J Cardiol 2013;168:3741-3746.

7 Tsai TT, et al: Safety and efficacy of drug-eluting stents in older patients with chronic kidney disease: a report from the linked CathPCI Registry-CMS claims database. J Am Coll Cardiol 2011;58:1859-1869.

8 Shenoy C, et al: Drug-eluting stents in patients with chronic kidney disease: a prospective registry study. PLoS One 2010;5:e15070.

9 National Kidney, F., K/DOQI clinical practice guidelines for chronic kidney disease: evaluation, classification, and stratification. Am J Kidney Dis 2002;39(2 suppl 1):S1-S266.

10 Cutlip DE, et al: Clinical end points in coronary stent trials: a case for standardized definitions. Circulation 2007;115:2344-2351.

11 Sadeghi HM, etal: Impact of renal insufficiency in patients undergoing primary angioplasty for acute myocardial infarction. Circulation 2003;108:2769-2775.

12 Osorio Gomes $\mathrm{V}$, et al: Impact of chronic kidney disease on the efficacy of drug-eluting stents: long-term followup study. Arq Bras Cardiol 2011;96:346-351.

13 Sarno G, et al: Lower risk of stent thrombosis and restenosis with unrestricted use of 'new-generation' drugeluting stents: a report from the nationwide Swedish Coronary Angiography and Angioplasty Registry (SCAAR). Eur Heart J 2012;33:606-613.

14 Barthelemy 0, et al: One-year clinical outcomes in patients with chronic renal failure treated by percutaneous coronary intervention with drug-eluting stent. Arch Cardiovasc Dis 2011;104:604-610.

15 El-Menyar AA, Al Suwaidi J, Holmes DR Jr: Use of drug-eluting stents in patients with coronary artery disease and renal insufficiency. Mayo Clin Proc 2010;85:165-171.

16 Hemmelgarn BR, et al: Survival after coronary revascularization among patients with kidney disease. Circulation 2004;110:1890-1895. 
Wańha et al.: Long-Term Percutaneous Coronary Intervention Outcomes of Patients with Chronic Kidney Disease in the Era of Second-Generation Drug-Eluting Stents

17 Goldenberg I, et al: Relation between renal function and outcomes in patients with non-ST-segment elevation acute coronary syndrome: real-world data from the European Public Health Outcome Research and Indicators Collection Project. Arch Intern Med 2010;170:888-895.

18 Manjunath G, et al: Level of kidney function as a risk factor for cardiovascular outcomes in the elderly. Kidney Int 2003;63:1121-1129.

19 Mathis AS, Gugger JJ: Percutaneous coronary intervention-related bleeding risk factors in current practice. Ann Pharmacother 2005;39:1627-1633.

20 Moukarbel GV, et al: Gastrointestinal bleeding in high risk survivors of myocardial infarction: the VALIANT Trial. Eur Heart J 2009;30:2226-2232.

21 Winter MP, et al: Personalized antiplatelet therapy with P2Y12 receptor inhibitors: benefits and pitfalls. Postepy Kardiol Interwencyjnej 2015;11:259-280.

22 Maier B, et al: Antithrombotic therapy in patients with atrial fibrillation and acute coronary syndrome in the real world: Data from the Berlin AFibACS Registry Cardiol J 2014;21:465-473.

23 Moses JW, et al: Sirolimus-eluting stents versus standard stents in patients with stenosis in a native coronary artery. N Engl J Med 2003;349:1315-1323.

24 Miao Y, et al: Chronic kidney disease and the risk of stent thrombosis after percutaneous coronary intervention with drug-eluting stents. Catheter Cardiovasc Interv 2012;80:361-367.

25 Sarno G, et al: Lower risk of stent thrombosis and restenosis with unrestricted use of "new-generation" drugeluting stents: a report from the nationwide Swedish Coronary Angiography and Angioplasty Registry (SCAAR). European Heart Journal 2012;33:606-613.

26 Valgimigli M, et al: Two-year outcomes after first- or second-generation drug-eluting or bare-metal stent implantation in all-comer patients undergoing percutaneous coronary intervention: a pre-specified analysis from the PRODIGY study (PROlonging Dual Antiplatelet Treatment After Grading stent-induced Intimal hyperplasia studY). JACC Cardiovasc Interv 2014;7:20-28.

27 Chan W, et al: Association between drug-eluting stent type and clinical outcomes in patients with chronic kidney disease undergoing percutaneous coronary intervention. Can J Cardiol 2014;30:1170-1176.

28 Wańha W, et al: Impact of anaemia on long-term outcomes in patients treated with first- and second-generation drug-eluting stents; Katowice-Zabrze Registry. Kardiol Pol 2016;74:561-569.

29 Kawecki D, et al: Comparison of First- and Second-Generation Drug-Eluting Stents in an All-Comer Population of Patients with Diabetes Mellitus (from Katowice-Zabrze Registry). Med Sci Monit 2015;21:3261-3269. 